\title{
Acute Effects of Vanadate Oligomers on Heart, Kidney, and Liver Histology in the Lusitanian Toadfish (Halobatrachus didactylus)
}

\author{
G. Borges, ${ }^{1}$ P. Mendonça, ${ }^{1}$ N. Joaquim, ${ }^{1}$ J. Coucelo, ${ }^{1}$ M. Aureliano ${ }^{2}$ \\ ${ }^{1}$ Comparative Cardiovascular Physiology Laboratory, Centro de Ciêncas do Mar, University of Algarve—Campus of Gambelas, $8000-810$ Faro, \\ Portugal \\ ${ }^{2}$ Centro Multidisciplinar de Química do Ambiente, Department of Chemistry and Biochemistry, Faculty of Sciences and Tecnhology, University of \\ Algarve-Campus de Gambelas, 8000-810 Faro, Portugal
}

Received: 31 July 2002/Accepted: 27 March 2003

\begin{abstract}
The contribution of vanadate oligomers to the acute histological effects of vanadium was analyzed in the heart, kidney, and liver of Halobatrachus didactylus (Schneider, 1801). A sublethal vanadium dose $(5 \mathrm{~m} M, 1 \mathrm{~mL} / \mathrm{kg})$ in the form of metavanadate (containing ortho and metameric species) or in the form of decavanadate (containing only decameric species) was intraperitoneally administered by injection, and specimens of $H$. didactylus were sacrificed at one and seven days postinjection. Sections of heart ventricle and renal and hepatic tissue were stained with hematoxylin-eosin and examined by light microscopy to identify vanadium-induced tissue injury. In addition, PicroSirius-stained ventricular sections were analyzed by bipolarized light microscopy to determine the fraction of myocardium occupied by the ventricular wall structural elements (collagen I, collagen III, and cardiac muscle). Both vanadate solutions produced similar effects in the renal tissue. Morphological alterations included damaged renal tubules showing disorganized epithelial cells in different states of necrosis. Reabsorbed renal tubules and hyperchromatic interstitial tissue were also observed. The hepatic tissue presented hyperchromatic and hypertrophied nuclei, along with necrotic and hypertrophied hepatocytes, and more severe changes were observed in the liver with exposure to decavanadate. Vanadate oligomers promoted evident tissue lesions in the kidney and liver, but not in the cardiac tissue. However, cardiac tissue structural changes were produced. For example, decavanadate induced a hypertrophy of the ventricle due to a decrease in the percentage of myocardium occupied by collagen fibers. In general, decavanadate was shown to be more toxic than metavanadate.
\end{abstract}

Vanadium is a widely distributed transition metal that is present in high concentrations in natural products such as crude oils, coal, and gasoline. Environmental exposure to vanadium

Correspondence to: J. Coucelo; email: jcoucelo@ualg.pt occurs mainly through the burning of these fossil fuels. Average concentration of vanadium in crude oils, which constitute a major pollution source in oceans, ranges from 3 to $257 \mu \mathrm{g} / \mathrm{g}$ (Nriagu 1998).

It is known that heavy metals affect several organs, especially the kidney and the liver, where numerous histopathological effects have been described. These include disorganization and hypochromia of renal tubule cell nuclei, picnotic lumen, and vacuolar areas in renal tubule cells, accumulation of amorphous eosinophilic material in the renal tubule nuclei, and reinforcement of reticular appearance in hepatocytes and leukocyte migration (Gutiérrez et al. 1978; Establier and Gutiérrez 1980; Sarasquete et al. 1982). Cardiovascular effects of heavy metals such as vanadium are also known, namely alterations of heart rate, cardiac inotropism, and peripheral vascular resistance (Boscolo et al. 1994; Carmignani et al. 1996), although histopathological effects in cardiac tissue are not completely understood.

In trace concentrations, vanadium may exert a wide range of beneficial effects in living organisms: for example, vanadium is used as therapy in diabetes, since it mimics the action of insulin (Nechay et al. 1986; Harland and Harden-Williams 1994; Barceloux 1999). In higher ( $\mu \mathrm{M})$ concentrations vanadium becomes toxic, and induces lipid peroxidation, DNA damage, sulphydryl group depletion, and alterations in calcium metabolism (Nechay et al. 1986; Viarengo 1989; Stohs and Bagchi 1995).

Most of the physiological importance of pentavalent vanadium $\left(\mathrm{V}^{+5}\right)$ is associated with monomeric vanadate $\left(\mathrm{H}_{2} \mathrm{VO}_{4}{ }^{-}\right.$; $\mathrm{HVO}_{4}{ }^{2-}$ ), probably due to similarities between phosphate and vanadate chemistries in the solution (Chasteen 1983). However, other vanadate species, with different states of protonation and conformation, can occur simultaneously in equilibrium in vanadate solutions. These include dimeric $\left(\mathrm{V}_{2} \mathrm{O}_{7}{ }^{4-}\right)$ and tetrameric $\left(\mathrm{V}_{4} \mathrm{O}_{12}{ }^{4-}\right)$ species, or even decameric species $\left(\mathrm{V}_{10} \mathrm{O}_{28}{ }^{6-}\right)$, which are known to either stimulate or inhibit the activity of several enzymes (Amado et al. 1993; Crans et al. 1995; Aureliano and Madeira 1998). It is well established that vanadate may enter certain cells by an anion transport mechanism and be reduced to vanadyl $(+4), \mathrm{VO}^{2+}$ by glutathione, 
catechols, cistein, NADH, NADPH, and ascorbic acid. Vanadyl is a relatively nonreactive form, due to its capacity to complex with proteins and small molecules (Nechay 1984; Barceloux 1999). However, the chemistry of $\mathrm{V}^{5+}$ in solution is very complex, and is a function of vanadate concentration, $\mathrm{pH}$, ionic strength, and the presence of several chemical compounds (Amado et al. 1993; Aureliano and Madeira 1994; Crans et al. 1995). In fact, vanadate reduction may be prevented if different vanadate oligomers are present. It was recently suggested that decameric vanadate species may eventually occur upon muscle cell acidification and that these species become accessible to specific protein binding sites (Tiago et al. 2002) and inaccessible to reduction, and induce different cellular responses than the other vanadate species (Aureliano et al. 2002). Therefore, a physiological role of decameric species in biological systems may be suggested. For example, it was recently shown that in vivo administration of $1 \mathrm{mg} / \mathrm{kg}$ of $5 \mathrm{mM}$ metavanadate and decavanadate solutions induced different effects on antioxidant enzyme activities, lipid peroxidation, and subcellular vanadium distribution in the cardiac tissue of Halobatrachus didactylus (the Lusitanian toadfish) (Aureliano et al. 2002), thus proving that the species of vanadate is important in vanadium toxicity.

It is becoming apparent that heavy metals primarily affect aquatic organisms that are exposed to environmental pollutants (Kelly et al. 1998). In fact, several works have reported that some fish species are far more sensitive to the toxic effects of heavy metals than mammals. Toxicological studies in fish species exposed to metals, such as cadmium, zinc, selenium, copper, and vanadium, are also almost exclusively limited to the evaluation of hepatic and renal injury (Palace and Klaverkamp 1993; Zikic et al. 1998; Vaglio and Landriscina 1999). In fact, there are only a few fish studies that examine the effect of heavy metal toxicity on cardiac tissue (Tort and Madsen 1991; Wang et al. 1999), and there are no studies on the myocardial histotoxicity of vanadate oligomers.

Since few biological studies involving vanadium consider the contribution of individual oligomeric vanadate species, the aim of this work was to analyze the contribution of different vanadate oligomers to the acute histological effects that vanadium has in the heart, kidney, and liver of Halobatrachus didactylus.

\section{Materials and Methods}

\section{Vanadate Solutions}

Metavanadate stock solution $(50 \mathrm{~m} M, \mathrm{pH}$ 6.7) was prepared from ammonium metavanadate (Riedel-de-Häen, Germany), while the decavanadate stock solution was obtained by adjusting the $\mathrm{pH}$ of the former solution to 4.0 (Aureliano and Madeira 1994). Immediately before using the solutions, they were diluted to a final concentration of $5 \mathrm{mM}$, using $0.9 \% \mathrm{NaCl}$ ( $\mathrm{pH} \mathrm{8.0)}$ ), and $\mathrm{pH}$ was adjusted to 7.0.

${ }^{51} \mathrm{~V}$ NMR spectral analysis indicated that, after dilution and adjustment to $\mathrm{pH} 7$, the decavanadate solution ( $5 \mathrm{mM}$ total vanadium) contained only decameric species, while the $5 \mathrm{mM}$ metavanadate solution contained monomeric (V1), dimeric (V2), tetrameric (V4), and pentameric (V5) species (Aureliano 2000; Soares et al. 2003). Moreover, UV/Vis spectrophotometric characterization of the decavanadate solution revealed two bands of absorbance (at 360 and $400 \mathrm{~nm}$ ). These bands correspond to the wavelengths where the absorbance of decameric vanadate species is maximum. The metavanadate solution exhibited no absorbance at $400 \mathrm{~nm}$ (Aureliano and Madeira 1998). It was verified spectrophotometrically, in an assay medium consisting of $0.9 \% \mathrm{NaCl}(\mathrm{pH} 8.0)$, that the deoligomerization of decameric species is slow: that is, the estimated half-life for a decavanadate solution $(1 \mathrm{mM}$ total vanadium) was $10 \mathrm{~h}$ (Soares et al. 2003). These observations guarantee that the injected decavanadate solution contained only decameric species.

\section{Fish}

Specimens of the marine teleost Halobatrachus didactylus (Lusitanian toadfish), of either sex, with an average ( \pm standard deviation) body mass and length of $360 \pm 106 \mathrm{~g}$ and $27.4 \pm 2.52 \mathrm{~cm}$, respectively, were caught from a noncontaminated area (FaroOlhão Inlet) of the Ria Formosa Lagoon (south coast of Portugal). During the acclimatization period (one month), the animals were fed squid and kept in 450-L tanks, with aerated, recirculating metal-free water at $20^{\circ} \mathrm{C}(\mathrm{pH} 7.9)$. In order to study the effects of the two vanadate solutions, metavanadate and decavanadate, the specimens were divided into the following three groups of 10 fish each: Control, Meta, and Deca. The Meta and Deca groups were injected with $1 \mathrm{~mL} / \mathrm{kg}$ of metavanadate or decavanadate solutions $(5 \mathrm{mM})$, respectively, and five specimens of each group were sacrificed 1 and $7 \mathrm{~d}$ postinjection. The Control group was not injected. During the experiment, the fish were not fed.

\section{Histological Analysis}

The fish were euthanized in 2-phenoxyethanol $(1 \mathrm{~mL} / \mathrm{L}$ seawater $)$ and the heart, kidney, and liver were collected. The heart and ventricles were weighed in order to calculate the relative cardiac mass-cardiac mass $(\mathrm{g}) /$ body mass $(\mathrm{g}) \times 100$ - and the relative ventricular massventricle mass $(\mathrm{g}) /$ body mass $(\mathrm{g}) \times 100$. All three organs were fixed in $10 \%$ formaldehyde for $48 \mathrm{~h}$, and representative samples (about $0.5-\mathrm{cm}$ thick) of heart ventricle, kidney, and liver were dehydrated in a series of increasing alcohol concentrations (from 70 to 100\%). The tissues were embedded in xylene and then in paraffin. Histological sections $5-\mu \mathrm{m}$ thick were obtained, and subjected to routine hematoxylin-eosin (HE) staining and PicroSirius staining to specifically identify collagen fibers. The HE-stained sections were examined using light microscopy $(\times 1000)$ to study tissue alterations induced by vanadium (qualitative analysis).

A quantitative analysis of alterations in ventricular wall components was performed on the PicroSirius-stained sections using bipolarized light microscopy, and $400 \times$ magnification. When this technique is used, collagen type I stains red and collagen type III stains green, due to their differing birefringence, muscle cells stain dark blue, and lacunae appear light blue. The area fractions occupied by the above components were quantified in successive images using Optimas Bioscan 6.5 software (Media Cybernetics, Silver Spring, MD, USA). Each of these images was a section through the entire ventricular wall, from the epicardium to the endocardium, and three randomly chosen axes through the ventricular wall were chosen for analysis in each animal (Coucelo et al. 2000).

\section{Statistical Analysis}

All data presented in the text and figures are means \pm standard deviation, and are based on data obtained from five individuals per 
group. Means for the proportion of ventricle wall occupied by each component were calculated using images recorded from all three axes of the ventricle wall (total of measurements: Control, day 1: $n=89$; Control, day 7: $n=181$; Meta, day 1: $n=109$; Meta, day 7: $n=245$; Deca, day 1: $n=109$; Deca, day 7: $n=272$ ). The nonparametric Mann-Whitney test was used to identify statistical differences $(p<0.05)$ between the groups, and all statistical analyses were performed using Sigma Stat 2.0 software (Jandel Corporation, San Rafael, CA, USA).

\section{Results}

The vanadate oligomers had different effects on heart and ventricular masses. In the Deca group, relative cardiac mass $(0.156 \pm 0.001 \%)$ and relative ventricular mass $(0.088 \pm$ $0.000 \%)$ increased significantly $(p<0.05)$ relative to the Control group $(0.118 \pm 0.001 \%$ and $0.064 \pm 0.000 \%$, respectively) seven days after exposure. In contrast, these parameters were not significantly affected in the Meta group after one or seven days of exposure.

In ventricles from the control group, five different areas within the ventricle wall were identified: the epicardium, the subepicardial layer, the myocardial layer, the subendocardial layer, and the endocardium (Fig. 1). A layer of flattened epithelium constituted the epicardium. The subepicardial layer contained connective tissue with large amounts of collagen type I and III, as well as fibroblasts and blood vessels. A thin layer of fibroadipose tissue was found underlying this connective tissue (Fig. 1a and d). The myocardial layer was lacunar, and entirely composed of trabeculated tissue with randomly arranged cardiac muscle fibers. Small amounts of collagen types I and III were spread throughout the whole myocardial layer (Fig. 1b and e). The subendocardial layer was similar in structure to the subepicardial layer, and a layer of endothelial cells formed the endocardium (Fig. 1c and f).

Vanadium treatment (either Deca or Meta) had no significant affect on the fractional area of the subepicardial or subendocardial tissues that was occupied by various tissue components, and no evidence of tissue lesions was found in any of the tissue layers. However, vanadium treatment had significant effects on the fractional area of myocardium that consisted of the different cardiac tissue components (collagen type I, collagen type III, muscle tissue, and lacunae).

In the myocardial layer, one day after exposure to metavanadate, collagen III ( $p<0.05$; Control group, $0.306 \pm 0.277 \%$; Meta group, $0.250 \pm 0.298 \%$ ) decreased significantly, whereas the fractional area occupied by muscle cells showed a significant increase $(p<0.05$; Control group, $45.6 \pm 11.1 \%$; Meta group, $51.4 \pm 7.4 \%$ ) (Fig. 2). Furthermore, seven days after injection with metavanadate, there was a significant decrease in the area fraction occupied by collagen I $(p<0.05$; Control group, $1.63 \pm 1.68 \%$; Meta group, $1.54 \pm 3.07 \%)$ and collagen III $(p<0.05$; Control group, $0.351 \pm 0.383 \%$; Meta group, $0.196 \pm 0.239 \%$ ) (Fig. 2).

One day after vanadium exposure, the Deca group had significantly diminished area fractions of collagen I $(p<0.05$; Control group, $2.16 \pm 2.32 \%$; Deca group, $0.675 \pm 0.787 \%)$ and collagen III $(p<0.05$; Control group, $0.306 \pm 0.277 \%$; Deca group, 0.194 $\pm 0.196 \%$ ). In contrast, the area occupied by muscle cells increased significantly $(p<0.05$; Control group, $45.6 \pm 11.1 \%$;
Deca group, $50.8 \pm 7.5 \%$ ) (Fig. 2). Seven days after exposure, there was also a significant decrease in the percentage of myocardial area occupied by collagen III $(p<0.05$; Control group, $0.351 \pm 0.383 \%$; Deca group, $0.204 \pm 0.266 \%$ ), and an increase in the area of muscle fibers $(p<0.05$; Control group, $50.2 \pm$ 11.1\%; Deca group, $54.3 \pm 8.7 \%$ ) (Fig. 2).

The kidney of $H$. didactylus is composed of nephrons and interstitial lymphoid tissue. In this species, the nephron lacks a renal corpuscle, and is thus only composed of renal tubules that consist of a single layer of epithelial cells (Fig. 3a). Following vanadate administration, the organization of the renal tissue was strongly affected. After one day of exposure, the kidney of metavanadate-injected specimens had a significant amount of damaged renal tubules. Extensively damaged renal tubules were characterized by epithelial cells, which showed complete disorganization and different states of necrosis (picnotic and karyolytic nuclei), and by interstitial tissue that was hyperchromatic (Fig. 3b). In addition, the normal circular appearance of the epithelial cells was significantly altered. The cells were agglomerated and it was impossible to detect lumina. Seven days after exposure to metavanadate, the kidney interstitium of $H$. didactylus contained hyperchromatic tissue and numerous empty spaces. These spaces are indicative of the removal of dead tubular cells (Fig. 3c). In the decavanadate-injected specimens, after one day of exposure, there was clear evidence of interstitial tissue hyperchromia, some hyperchromatic renal tubules were found, and other tubules contained disorganized and necrotic epithelial cells (picnotic and karyolytic nuclei) (Fig. 3d). After seven days of exposure to decavanadate, the interstitial tissue was hyperchromatic and also showed signs of tubular cell reabsorption (Fig. 3e). Therefore, seven days after exposure to the vanadate solutions, the alterations in the renal tissue appeared to be more severe than after one day. On the other hand, metavanadate and decavanadate produced similar effects.

H. didactylus has a hepatopancreas, which is an organ where both hepatic and pancreatic cells coexist. The hepatic cells have small vacuolar structures that correspond to glycogen and lipids stores, and both the number and size of these structures show a considerable degree of individual variation (Fig. 4a). Examination of HE-stained sections using light microscopy revealed a number of tissue alterations in the vanadium-treated toadfish. After one and seven days of exposure to metavanadate, the hepatocytes presented hyperchromatic nuclei (Fig. 4b and c). On the other hand, after decavanadate injection, some hypertrophied nuclei and hypertrophied hepatocytes were found, along with necrotic hepatocytes. In general, the hepatocytes of the vanadium-treated fish appeared to have a lower cytoplasmic content. More severe effects were observed following decavanadate intoxication and after seven days of exposure (Fig. 4d and e).

\section{Discussion}

The cardiac tissue components normally exist in a state of equilibrium that is based on their relative proportions, structural integrity, physical arrangement, and biochemical characteristics. This equilibrium plays a fundamental role in maintaining the heart's inotropic capacity and in assuring myocardiocyte functional efficiency (Weber and Eghbali 

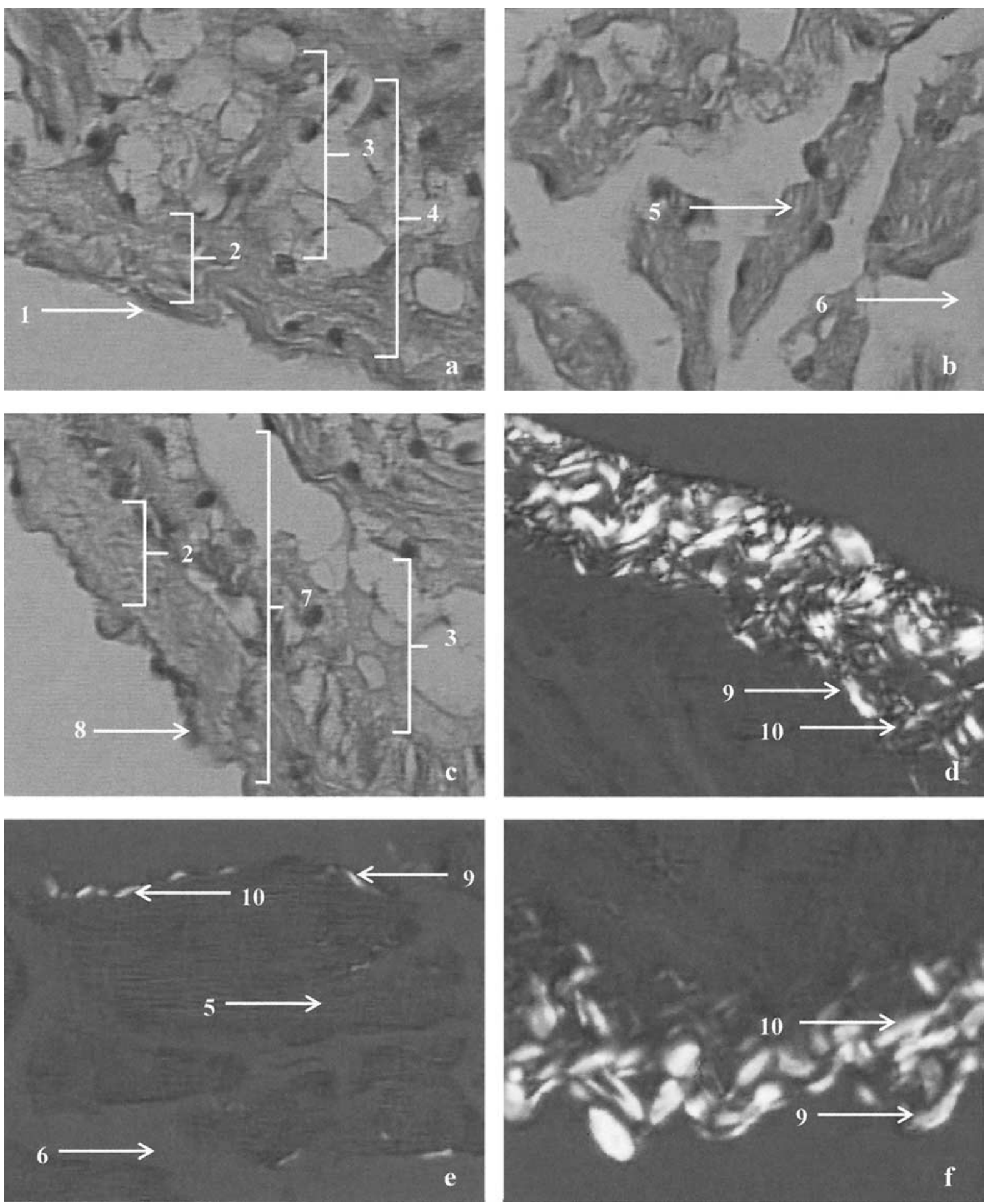

Fig. 1. Transverse sections of the ventricular wall of $H$. didactylus. These HE-stained sections were viewed at $400 \times$ magnification using light microscopy: (a) section containing the subepicardial region; (b) section containing the myocardial region; (c) section containing the subendocardial region, which was also stained with PicroSirius and viewed with bipolarizing microscopy; (d) section containing the subepicardial region; (e) section containing the myocardial region; (f) section containing the subendocardial region. 1, epicardium; 2, connective tissue layer; 3, fibroadipose tissue layer; 4, subepicardial region; 5, muscle tissue; 6, lacuna; 7, subendocardial region; 8 , endocardium; 9, collagen type I; 10, collagen type III 

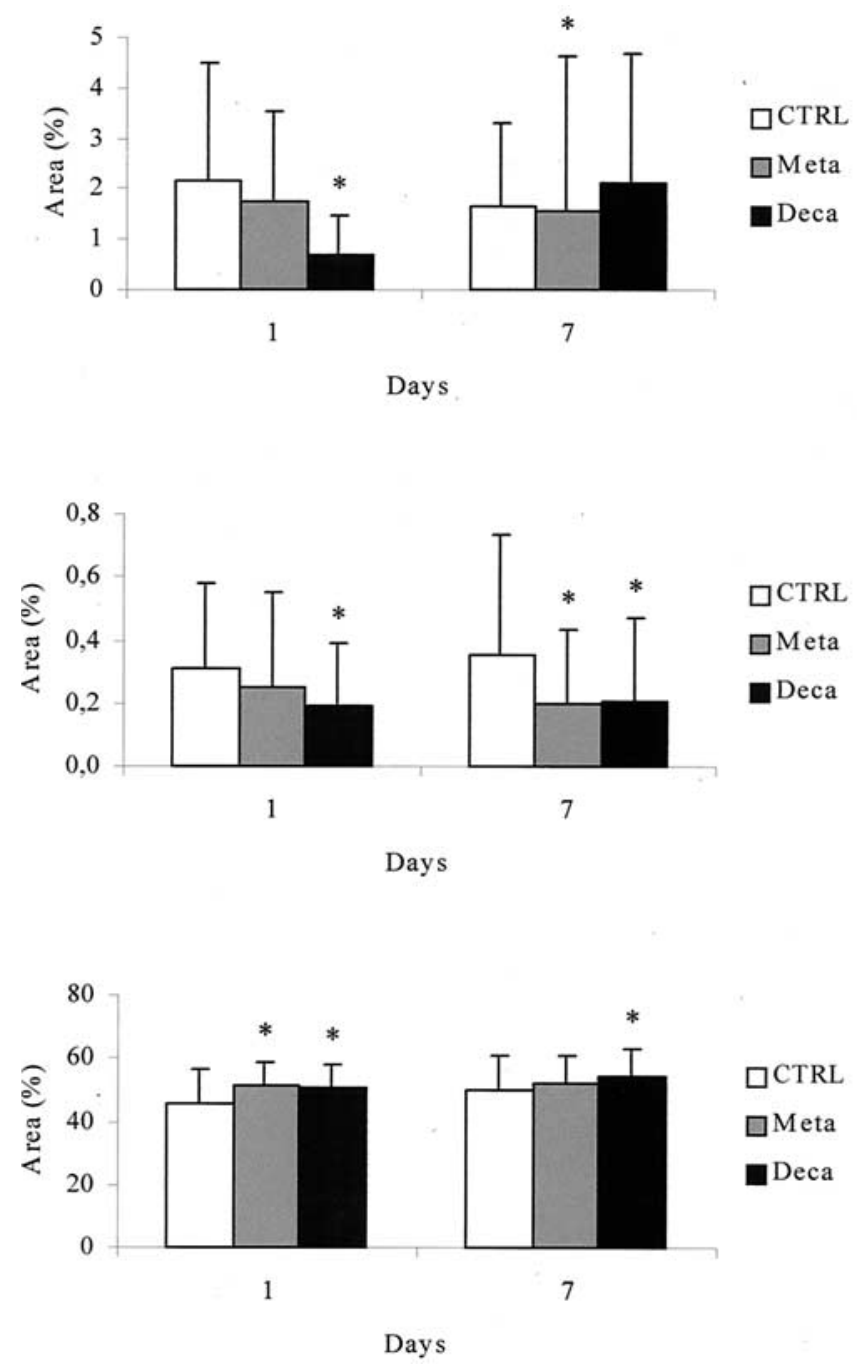

Fig. 2. Fractional area (\%) of myocardial images that was composed by the various tissue components: (a) collagen type I; (b) collagen type III; (c) muscle tissue (*significantly different from control, $p<0.05$ )

1991). In this regard, there is a strict relationship between cardiac tissue morphological integrity and the maintenance of adequate heart activity (Coucelo et al. 1998). Different physiopathological conditions are associated with structural alterations in the cardiac tissue components, both at the level of connective tissue and at the level of muscular tissue, and vary from remodeling to hypertrophy (Sanchez-Quintana et al. 1995; Tota and Gattuso 1996). Therefore, characterization of the myocardial tissue may be important in evaluating the degree of cellular damage caused by exposure to toxic agents.

Extracellular collagen is an extremely stable structural protein that is highly resistant to all proteinases, with the exception of specific collagenases (Caulfield and Janicki 1997). Previous studies have shown that myocardial collagen is rapidly degraded in the presence of activated collagenases, that this results in ventricular dilatation, increased compliance, and shape changes, and that these alterations are observed in several pathologic conditions (O'Brien and Moore 1966; Caulfield and Janicki 1997). Decavanadate- treated toadfish showed an increase in relative cardiac and ventricular masses, and simultaneous-but oppositechanges in the fractional myocardial area composed of collagen (decrease) and muscle fibers (increase). Further, because the effects were more pronounced in Deca, versus Meta, group fish, our results suggest that exposure to oligomeric vanadate species may interfere with collagen metabolism, and induce ventricle remodeling. These results are consistent with studies on $H$. didactylus specimens intraperitoneally injected with $1 \mathrm{mg} / \mathrm{kg}$ of $\mathrm{CdCl}_{2}$, which showed no detectable myocardial injury or evidence of increased repair tissue, but found that muscle fibers occupied a higher fraction of myocardial area (Coucelo et al. 2000). Carmignani et al. (1996) studied the effects of adding $1 \mu \mathrm{g} / \mathrm{mL}$ of vanadate to the drinking water of male rabbits, and did not find morphological alterations in the cardiac tissue. However, several chronic studies, using rats that were forced to drink water with $100 \mathrm{ppm}$ vanadium, have shown hypertension and/or augmented peripheral vascular resistance (Carmignani et al. 1996). Further, male rats subjected to 1, 10, or 40 $\mu \mathrm{g} / \mathrm{mL}$ of sodium metavanadate in their drinking water also showed a dose-independent increase in systolic and diastolic blood pressures, while heart rate and cardiac inotropism were not affected (Boscolo et al. 1994). These rats had diminished renal function, with alterations in the urinary excretion of electrolytes and in the activities of the kallikrein-kinin and the renin-angiotensin-aldosterone systems. In the rats exposed to 10 and $40 \mu \mathrm{g} / \mathrm{mL}$ of vanadium, the lumens of the proximal tubules were narrowed and contained amorphous material, and hydropic degeneration was also described in some proximal and distal tubules.

In this study, exposure to vanadate oligomers caused tissue damage in both the kidney and the liver, and these alterations were more severe in the individuals exposed to decavanadate. $H$. didactylus specimens exposed to $50 \mathrm{ppm}$ of $\mathrm{CdCl}_{2}$ in the water, for $96 \mathrm{~h}$, also showed histopathological alterations in both the kidney and liver (Gutiérrez et al. 1978). These alterations included disorganization and hypochromia of renal tubule cell nuclei, accumulation of amorphous eosinophilic material in renal tubule nuclei, and reinforcement of reticular appearance in hepatocytes. Establier and Gutiérrez (1980) observed cellular disorganization and vacuolar areas in the kidney, picnotic nuclei, as well as vacuolization in the liver of two different fish (Dicentrarchus labrax and Sparus aurata) exposed to cadmium. There is also evidence that inorganic mercury affects the kidney of $H$. didactylus. For example, although Sarasquete et al. (1982) showed that the apical area of renal tubule epithelial cells was not affected by exposure to waterborne $\mathrm{HgCl}_{2}$, they found clear evidence of nuclear depolarization, and cytoplasmatic vacuolization.

In the present work, we report for the first time that exposure to different vanadate oligomers induces morphological changes in cardiac, renal, and hepatic tissues in the experimental model $H$. didactylus. Vanadate oligomers caused tissue lesions in the kidney and liver, but not in cardiac tissue. However, decavanadate administration did induce a decrease in the fractional area of myocardium occupied by collagen fibers, leading to a hypertrophy of the ventricle. Based on these observations, we suggest that the morphological effects of vanadate on this tissue are mainly 

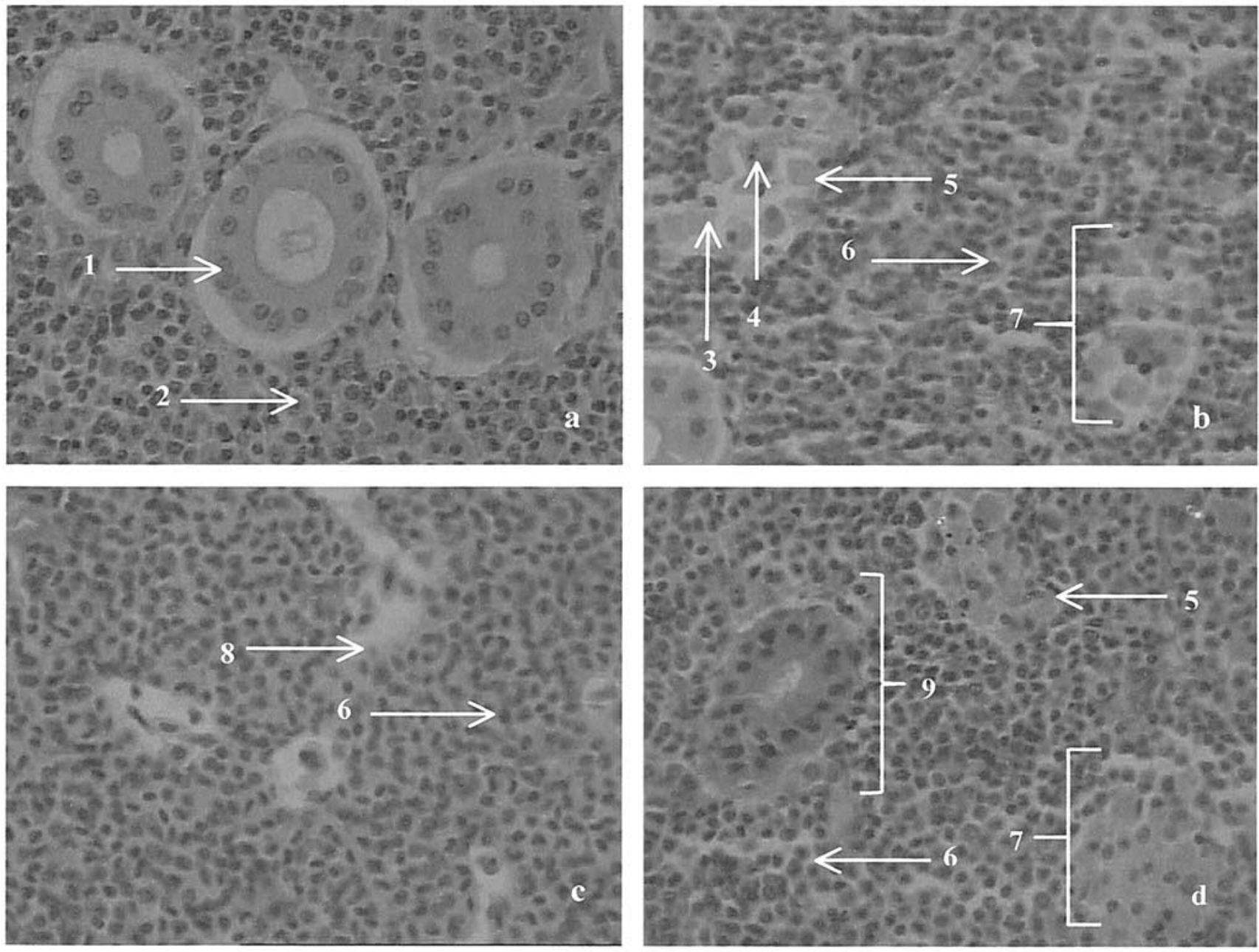

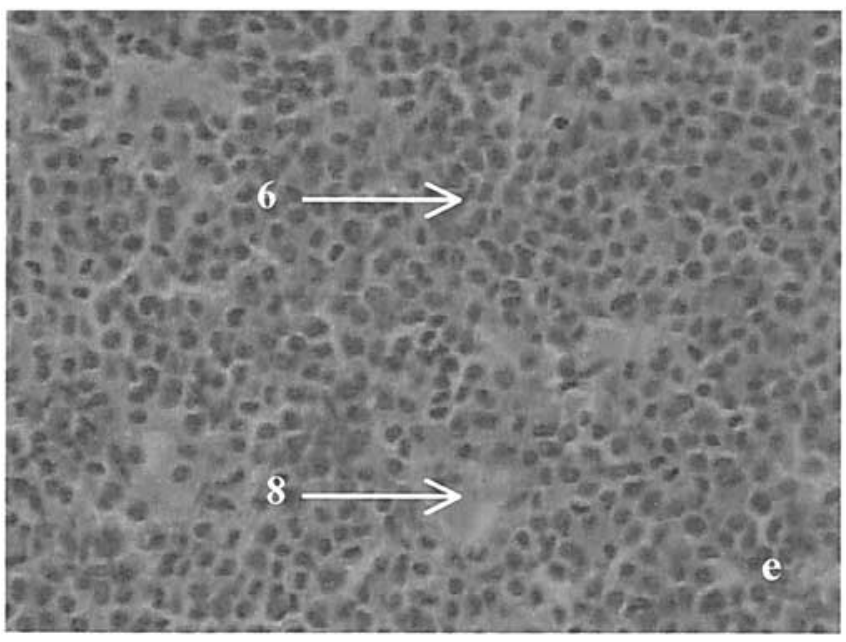

associated with cell volume alterations. In fact, several studies report vanadate inhibition of membrane protein function, namely E1-E2 ATPases (Aureliano and Madeira 1998), and thus a disruption of cell homeostasis. However, the in vivo mechanisms involved in the described morphological alterations need to be further explored.

In general, decavanadate exposure seems to induce more severe
Fig. 3. HE-stained renal tissue sections $(400 \times$ magnification): (a) kidney of a noninjected specimen; (b) kidney of specimen injected with metavanadate solution, one day after exposure; (c) kidney of specimen injected with metavanadate solution, seven days after exposure; (d) kidney of specimen injected with decavanadate solution, one day after exposure; (e) kidney of specimen injected with decavanadate solution, seven days after exposure. 1 , renal tubule; 2 , interstitial tissue; 3 , necrotic epithelial cell with picnotic nucleus; 4, necrotic epithelial cell with karyorrhetic nucleus; 5 , necrotic epithelial cell with karyolytic nucleus; 6 , hyperchromatic interstitial tissue; 7 , disorganized renal tubule; 8 , empty areas correspondent to absorbed renal tubules; 9 , hyperchromatic renal tubule

alterations than metavanadate, strongly suggesting that metal speciation regulates metal interactions with biological systems.

Acknowledgments. Gisela Borges was supported by a research grant from Unidade de Intervenção Cardiovascular do Hospital Particular do Algarve. 

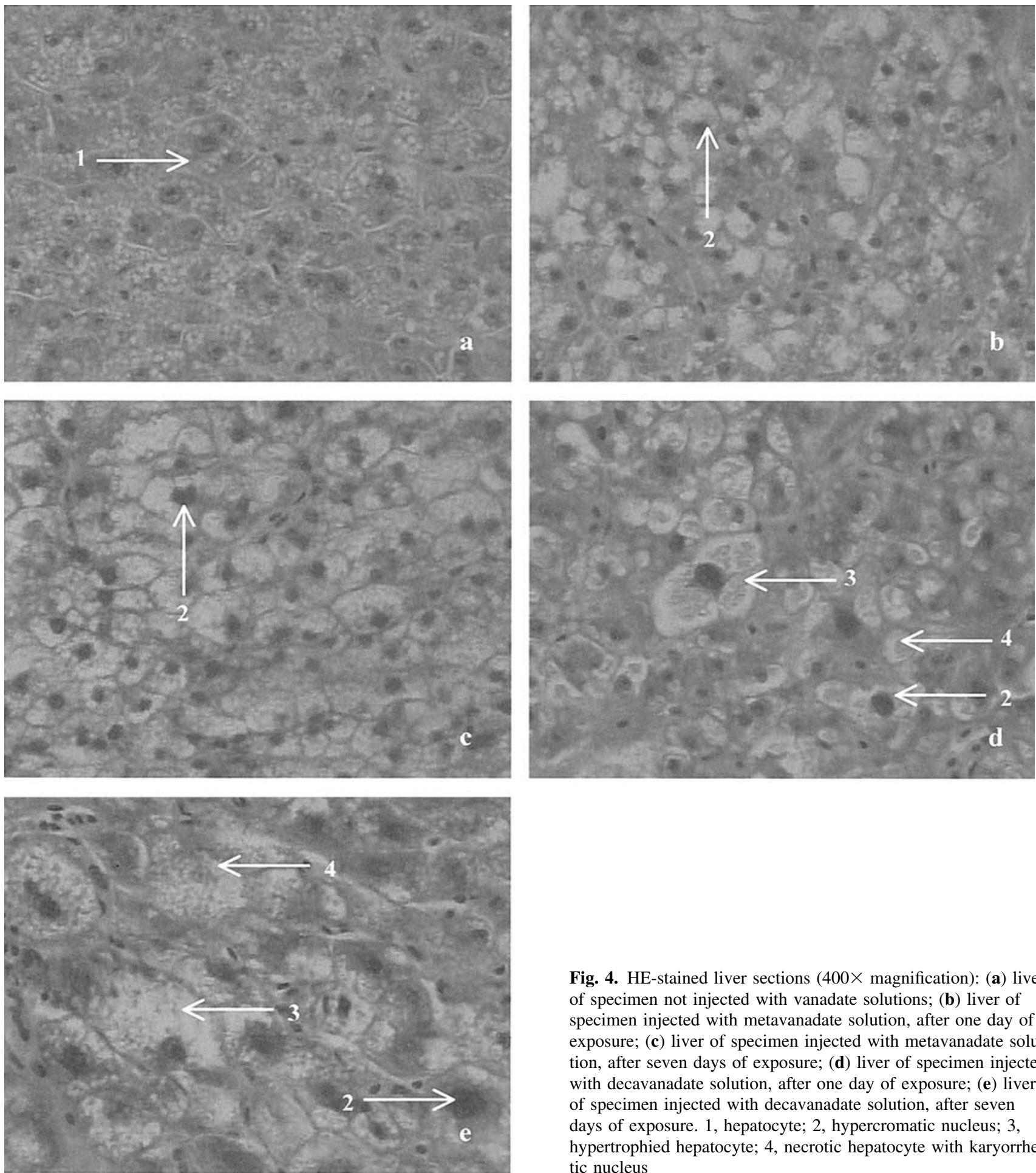

Fig. 4. HE-stained liver sections (400× magnification): (a) liver of specimen not injected with vanadate solutions; (b) liver of specimen injected with metavanadate solution, after one day of exposure; (c) liver of specimen injected with metavanadate solution, after seven days of exposure; (d) liver of specimen injected with decavanadate solution, after one day of exposure; (e) liver of specimen injected with decavanadate solution, after seven days of exposure. 1 , hepatocyte; 2 , hypercromatic nucleus; 3 , hypertrophied hepatocyte; 4 , necrotic hepatocyte with karyorrhetic nucleus

\section{References}

Amado A, Aureliano M, Ribeiro-Claro P, Teixeira-Dias J (1993)

Combined Raman and ${ }^{51} \mathrm{~V}$ NMR spectroscopic study of vanadium (V) oligomerization in aqueous alkaline solutions. J Raman Spect 24:699-703

Aureliano M, Madeira VMC (1994) Vanadate oligoanions interact

with the proton ejection by the $\mathrm{Ca}^{2+}$ pump of sarcoplasmic reticulum. Biochem Biophys Res Commun 205:161-167

Aureliano M, Madeira V (1998) Energy transduction mechanisms as affected by vanadium (V) species: $\mathrm{Ca}^{2+}$-pumping in sarcoplasmic reticulum. In: Nriagu J (ed) Vanadium in the environment. Part 1: Chemistry and biochemistry. Wiley and Sons, New York, pp 333-357 Aureliano M (2000) Vanadate oligomer inhibition of passive and 
active $\mathrm{Ca}^{2+}$ translocation by the $\mathrm{Ca}^{2+}$ pump of sarcoplasmic reticulum. J Inorg Biochem 80:145-147

Aureliano M, Joaquim N, Sousa A, Martins H, Coucelo JM (2002) Oxidative stress in toadfish (Halobactrachus didactylus) cardiac muscle: Acute exposure to vanadate oligomers. J Inorg Biochem 90:159-165

Barceloux D (1999) Vanadium. Clin Toxicol 37:265-278

Boscolo P, Carmignani M, Volpe A, Felaco M, del Rosso G, Porcelli G, Giuliano G (1994) Renal toxicity and arterial hypertension in rats chronically exposed to vanadate. Occup Environ Med 51: $500-503$

Carmignani M, Volpe AR, Masci O, Boscolo P, Giacomo F, Grilli A, del Rosso G, Felaco M (1996) Vanadate as factor of cardiovascular regulation by interactions with the catecholamine and nitric oxide systems. Biol Trace Elem Res 51:1-12

Caulfield JB, Janicki JS (1997) Structure and function of myocardial fibrillar collagen. Technol Health Care 5:95-113

Chasteen N (1983) The biochemistry of vanadium. Struct Bond 53: $105-138$

Coucelo JM, Joaquim N, Correia V, Azevedo J, Coucelo JA (1998) Análise histológica de alterações induzidas experimentalmente por cádmio no tecido muscular cardíaco através de método computadorizado de análise de imagem. Rev Port Cardiol 17:735-740

Coucelo JM, Joaquim N, Correia V, Bebianno MJ, Coucelo JA (2000) Cellular responses to cadmium toxicity in the heart, kidney and liver of Halobatrachus didactylus. Ecotoxicol Environ Rest 3:29-35

Crans DC, Mahroof-Tahir M, Keramidas AD (1995) Vanadium chemistry and biochemistry of relevance for use of vanadium componds as antidiabetic agents. Mol Cell Biochem 153:17-24

Establier R, Gutiérrez M (1980) Acumulation de cadmio a partir del agua de mar por el róbalo Dicentrarchus labrax; y la dorada Sparus aurata y sus efectos histopatológicos. Invest Pesq 44: $43-54$

Gutiérrez M, Establier R, Arias A (1978) Acumulación y efectos histopatológicos del cadmio y el mercurio en el sapo (Halobatrachus didactylus). Invest Pesq 42:141-154

Harland B, Harden-Williams B (1994) Is vanadium of human nutritional importance yet? J Am Diet Assoc 94:891-894

Kelly SA, Havrilla CM, Brad, TC Abramo KH, Levin ED (1998) Oxidative stress in toxicology: Established mammalian and emerging piscine model systems. Environ Health Perspect 106: 375-376

Nechay B (1984) Mechanisms of action of vanadium. Annu Rev Pharmacol Toxicol 24: 501-524

Nechay B, Nanninga L, Nechay P, Post R, Grantham J, Macara I, Kubena L, Philips T, Nielsen F (1986). Role of vanadium in biology. Fed Proc 45:123-132
Nriagu JO (1998) History, occurrence, and uses of vanadium. In: Nriagu JO (ed) Wiley and Sons, New York, pp 1-23

O'Brien LJ, Moore CM (1966) Connective tissue degradation and distensibility characteristics of the non-living heart. Experimentia 22:845-847

Palace VP, Klaverkamp JF (1993) Variation of hepatic enzymes in three species of freshwater fish from precambrian shield lakes and the effect of cadmium exposure. Comp Biochem Physiol C 104: $147-154$

Sanchez-Quintana D, Garcia-Martinez V, Climent V, Hurle JM (1995) Morphological analysis of the fish heart ventricle: Myocardial and connective tissue architecture in teleost species. Ann Anat 177: 267-274

Sarasquete MC, Gutiérrez M, Establier R (1982) Efecto del mercurio inorgánico $\left(\mathrm{HgCl}_{2}\right)$ sobre la sangre y riñon del sapo marino, Halobatrachus didactylus (Schneider, 1981). Invest Pesq 46:323330

Soares SS, Aureliano M, Joaquim N, Coucelo JM (2003) Cadmium and vanadate oligomers comparative effects on methaemoglobin reductase activity from Lusitanian toadfish: in vivo and in vitro studies. J Inorg Biochem 94:285-290

Stohs S, Bagchi D (1995) Oxidative mechanisms in the toxicity of metal ions. Free Radic Biol Med 18:321-336

Tiago T, Aureliano M, Gutiérrez-Merino C (2002) Quenching of myosin intrinsic fluorescence unravels the existence of a high affinity binding site for decavanadate. J Fluorescence 12:87-90

Tort L, Madsen LT (1991) The effects of the heavy metals cadmium and zinc on the contraction of ventricular fibres in fish. Comp Biochem Physiol 99:353-356

Tota B, Gattuso A (1996) Heart ventricle pumps in teleosts and elasmobranchs: A morphological approach. J Exp Zool 275:162171

Vaglio A, Landriscina C (1999) Changes in liver enzyme activity in the teleost Sparus aurata in response to cadmium intoxication. Ecotoxicol Environ Saf 43:111-116

Viarengo A (1989) Heavy metals in marine invertebrates: Mechanisms of regulation and toxicity at the cellular level. Crit Rev Aquat Sci 1:295-317

Wang R, Wang X, Wu L, Mateescu M (1999) Toxic effects of cadmium and copper on the isolated heart of dogfish shark, Squalus acanthias. J Toxicol Environ Health Part A 57:507-519

Weber KT, Egbali M (1991) Collagen matrix synthesis and degradation in the development and regression of left ventricular hypertrophy. Cardiovasc Rev Rep 12: 61-69

Zikik RV, Stain AS, Ognjanovic BI, Saicic ZS, Kostic MM, Pavlovic SZ, Petrovic VM (1998) The effect of cadmium and selenium on the antioxidant enzyme activities in rat heart. J Environ Pathol Toxicol Oncol 17:259-264 